\title{
Molecular characterization and genetic diversity of four
}

\section{undescribed novel oleaginous Mortierella alpina strains from}

\section{Libya [version 1; peer review: 3 approved]}

\author{
Fuzia Elfituri Muftah Eltariki, Kartikeya Tiwari (D), Mohammed Abdelfatah Alhoot (iD
}

Microbiology and Post Graduation Center, Management and Science University, Shah Alam, Selangor, 40100, Malaysia

V1 First published: 07 Sep 2021, 10:895

https://doi.org/10.12688/f1000research.70644.1

Latest published: 07 Sep 2021, 10:895

https://doi.org/10.12688/f1000research.70644.1

\section{Abstract}

Background: A large number of undiscovered fungal species still exist on earth, which can be useful for bioprospecting, particularly for single cell oil (SCO) production. Mortierella is one of the significant genera in this field and contains about hundred species. Moreover, $M$. alpina is the main single cell oil producer at commercial scale under this genus.

Methods: Soil samples from four unique locations of North-East Libya were collected for the isolation of oleaginous Mortierella alpina strains by a serial dilution method. Morphological identification was carried out using light microscopy (Olympus, Japan) and genetic diversity of the isolated Mortierella alpina strains was assessed using conserved internal transcribed spacer (ITS) gene sequences available on the NCBI GenBank database for the confirmation of novelty. The nucleotide sequences reported in this study have been deposited at GenBank (accession no. MZ298831:MZ298835). The MultAlin program was used to align the sequences of closely related strains. The DNA sequences were analyzed for phylogenetic relationships by molecular evolutionary genetic analysis using MEGA $X$ software consisting of Clustal_X v.2.1 for multiple sequence alignment. The neighbourjoining tree was constructed using the Kimura 2-parameter substitution model.

Results: The present research study confirms four oleaginous fungal isolates from Libyan soil. These isolates (barcoded as MSU-101, MSU201, MSU-401 and MSU-501) were discovered and reported for the first time from diverse soil samples of district Aljabal Al-Akhdar in North-East Libya and fall in the class: Zygomycetes; order: Mortierellales

Conclusions: Four oleaginous fungal isolates barcoded as MSU-101, MSU-201, MSU-401 and MSU-501 were identified and confirmed by morphological and molecular analysis. These fungal isolates showed highest similarity with Mortierella alpina species and can be potentialistic single cell oil producers. Thus, the present research

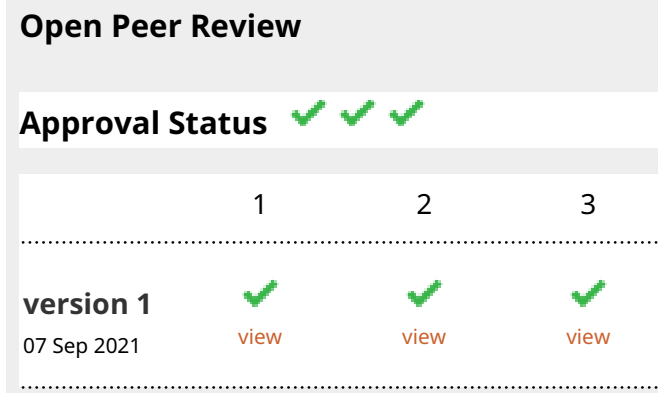

1. Kavindra Kumar Kesari, Aalto University, Espoo, Finland

2. Digpal Singh Gour, University of Idaho,

Moscow, USA

University of Idaho, Moscow, USA

3. Abhijeet Singh, Manipal University Jaipur, Jaipur, India

Any reports and responses or comments on the article can be found at the end of the article. 
study provides insight to the unseen fungal diversity and contributes to more comprehensive Mortierella alpina reference collections worldwide.

\section{Keywords}

Single cell oil, Mortierella alpina, Potato dextrose agar, Sporangiospore, Mortierellales

Corresponding authors: Kartikeya Tiwari (kartikeya_tiwari@msu.edu.my), Mohammed Abdelfatah Alhoot (malhoot@msu.edu.my)

Author roles: Muftah Eltariki FE: Data Curation, Investigation, Validation; Tiwari K: Conceptualization, Data Curation, Formal Analysis, Investigation, Methodology, Supervision, Validation, Writing - Original Draft Preparation, Writing - Review \& Editing; Alhoot MA: Conceptualization, Investigation, Methodology, Project Administration, Supervision, Validation, Visualization

Competing interests: No competing interests were disclosed.

Grant information: This work was supported by the Management and Science University (MSU) under grant numbers: SG-376-0216-IMS and SG-036-012019-IMS (Reference: RMC01/01/14092020/1). Funds from grant number SG-036-012019-IMS (Reference:

RMC01/01/14092020/1) were used for genetic characterization and assessment of genetic diversity of Mortierella alpina strains whereas, the funds from grant number SG-376-0216-IMS were used for isolation, identification and purchase of reagents for morphological identification of these strains. Since these both are seed grants thus, have limited funds and the funders had no role in study design, data collection, analysis, decision to publish and preparation of the manuscript.

The funders had no role in study design, data collection and analysis, decision to publish, or preparation of the manuscript.

Copyright: ( 2021 Muftah Eltariki FE et al. This is an open access article distributed under the terms of the Creative Commons Attribution License, which permits unrestricted use, distribution, and reproduction in any medium, provided the original work is properly cited.

How to cite this article: Muftah Eltariki FE, Tiwari K and Alhoot MA. Molecular characterization and genetic diversity of four undescribed novel oleaginous Mortierella alpina strains from Libya [version 1; peer review: 3 approved] F1000Research 2021,10 :895 https://doi.org/10.12688/f1000research.70644.1

First published: 07 Sep 2021, 10:895 https://doi.org/10.12688/f1000research.70644.1 


\section{Introduction}

Edible oils produced by oleaginous microorganisms are named as single cell oils (SCO). Most of these oil accumulating microorganisms are species of yeast and fungi. The comprehensive nuclear ribosomal deoxyribonucleic acid (DNA) molecular phylogeny analysis reported that the order Mortierellales contains nearly 100 described species and the Mortierellaceae family contains about 13 genera. M. alpina is one of the main single cell oil producing species/ arachidonic acid producing at commercial scale under Mortierella genus. (Coemans 1863; Hibbett et al. 2007; Hoffman et al. 2013; Spatafora et al. 2016; Wagner et al. 2013). Wang et al. (2011) described the M. alpina genome scale reconstructed metabolic model for higher production of arachidonic acid at industrial scale. Scientists are in continuous search for the new species/novel strains and trying hard to crack the reconstruction genome code to exploit these species, so that the arachidonic acid production can be simplified and commercialized with an improved protocol (Shin et al. 1994; Rhie et al. 2002; Rhie and Park 2001; Ha et al. 2004).

Oleaginous fungi especially Mortierella species are ubiquitous, saprophytic and belong to zygomycetes class. The polyunsaturated fatty acids (PUFA) production potential makes these fungi unique and significant to oil producing industries. Modern internal transcribed spacer based taxonomical classification (Kirk 1997; Linnemann 1941; Degawa and Gams 2004; Ariyawansa et al. 2015) categorizes the Mortierella genus into seven groups: selenospora and parvispora", "verticillata-humillis", "lignicola", "mutabillis, globulifera and angusta", "strangulate and wolfii", "alpina and polycephala", and "gamsii".

During our studies on Libyan Mortierellaceous fungi, we have isolated many diverse species. Surprisingly, four species of Mortierella we have encountered in Libya have not yet been reported. To our knowledge, this is the first report on these oleaginous fungal species from this country.

\section{Methods}

Collection of soil samples and isolation of fungi

This study was carried out in December 2017. In total, four different locations viz. Marawah, Albayda, Faydiyah and Suluntah located in district Aljabal Al-Akhdar, North-East Libya were chosen as shown in Table 1. In total, a $10 \mathrm{~g}$ rhizosphere soil sample from each location was collected in sterilized polybags and transported to the microbiology laboratory of Management and Science University, Shah Alam, Malaysia and stored at $4^{\circ} \mathrm{C}$ for further processing.

The fungal isolation was carried out by a conventional serial dilution technique in which $1 \mathrm{~g}$ of soil was mixed with $9 \mathrm{~mL}$ of sterile distilled water and shaken for $15 \mathrm{~min}$ at $25^{\circ} \mathrm{C}$; serial dilutions ranging from $10^{-1}$ to $10^{-4}$ were made. An aliquot of $0.1 \mathrm{~mL}$ from each dilution was transferred to potato dextrose agar supplemented with $100 \mu \mathrm{g}$ chloramphenicol/mL antibiotic and incubated at $25^{\circ} \mathrm{C}$ for $3-7$ days.

\section{Morphological identification}

Morphological features of the fungus were observed on potato dextrose agar (PDA) medium after one-point inoculation in 9-cm petri dishes and incubation at $25^{\circ} \mathrm{C}$ for 5-7 days (Hyde et al. 2016). The samples were inoculated with the help of a sterilized inoculation needle by center point inoculation on the PDA media containing petri dishes. All methods were performed at the laminar air flow by maintaining all aseptic conditions to avoid any kind of contamination using standard protocol described by Lee et al. (2017). The Petri dishes were sealed by parafilm and incubated for 5-7 days at $25^{\circ} \mathrm{C}$ in the dark for the growth of novel fungal species. All four distinct isolated fungal species were kept on plastic Petri dishes ( $9 \mathrm{~cm}$ diameter). These plates were observed on daily basis and their morphological characteristics viz. colony appearance, pigmentation, growth pattern, colony colour (front and reverse), colony diameters were documented. Individual colonies of fungi that showed varying morphologies were picked up and identified by mycokeys 3.0 version. The morphological features of four fungal isolates were compared with distinguished monographs precisely with II Subgenus: Mortierella; 2. Section ALPINA Linnem. Mucorineen-Gatt. Mortierella: 35. 1941 monograph (Gams 1977) to assess the novelty as shown in Table 2.

Direct microscopic identification was performed by using distilled water (wet mount technique) in which, a clean glass slide was labelled in the middle portion by marker and a drop of sterilized distilled water was put in on the marked middle portion, aerial spores and vegetative hyphae of the fungal isolate taken with the help of sterilized inoculation needle and distributed evenly within the water drop. Subsequently the glass coverslip was carefully added on the preparation in such a way that there was no air bubble formed. Same procedure was applied with lactophenol solution for identification of distinguished structures and prepared slides were examined under a light microscope at $40 \times$ magnification (Model: SZX16 Olympus, Japan). The sporangiophore, sporangium and sporangiospores, shape and size, developmental pattern, mature and immature sporangiospores, intercalary chlamydospore were measured and documented (White et al. 1990). Pure cultures of four fungal isolates were preserved and maintained (Fully grown barcoded 


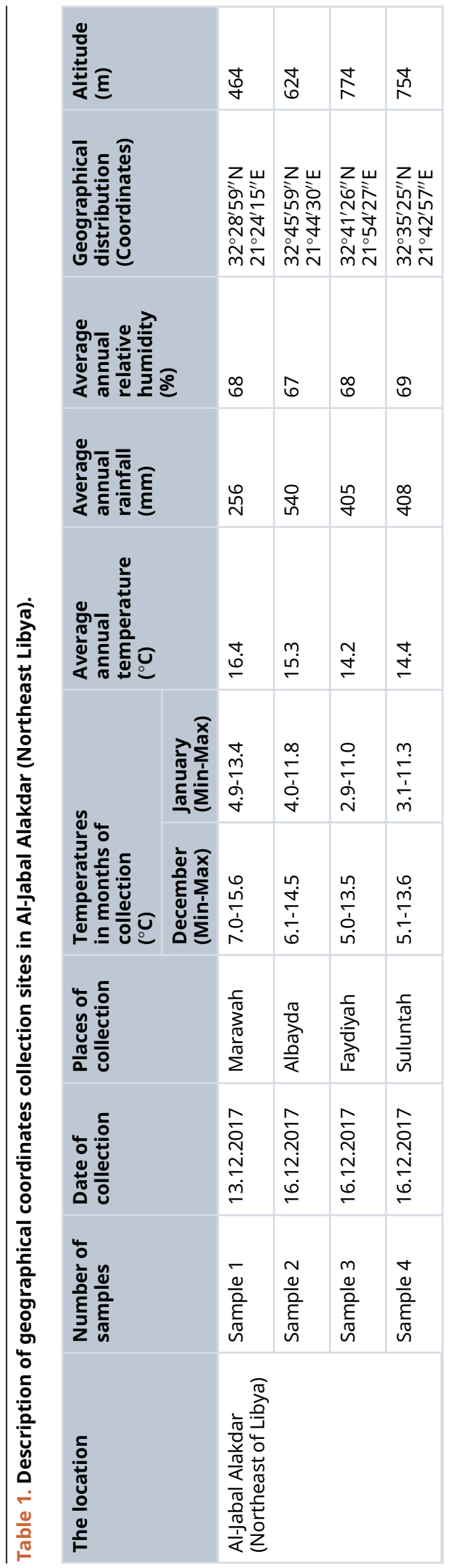




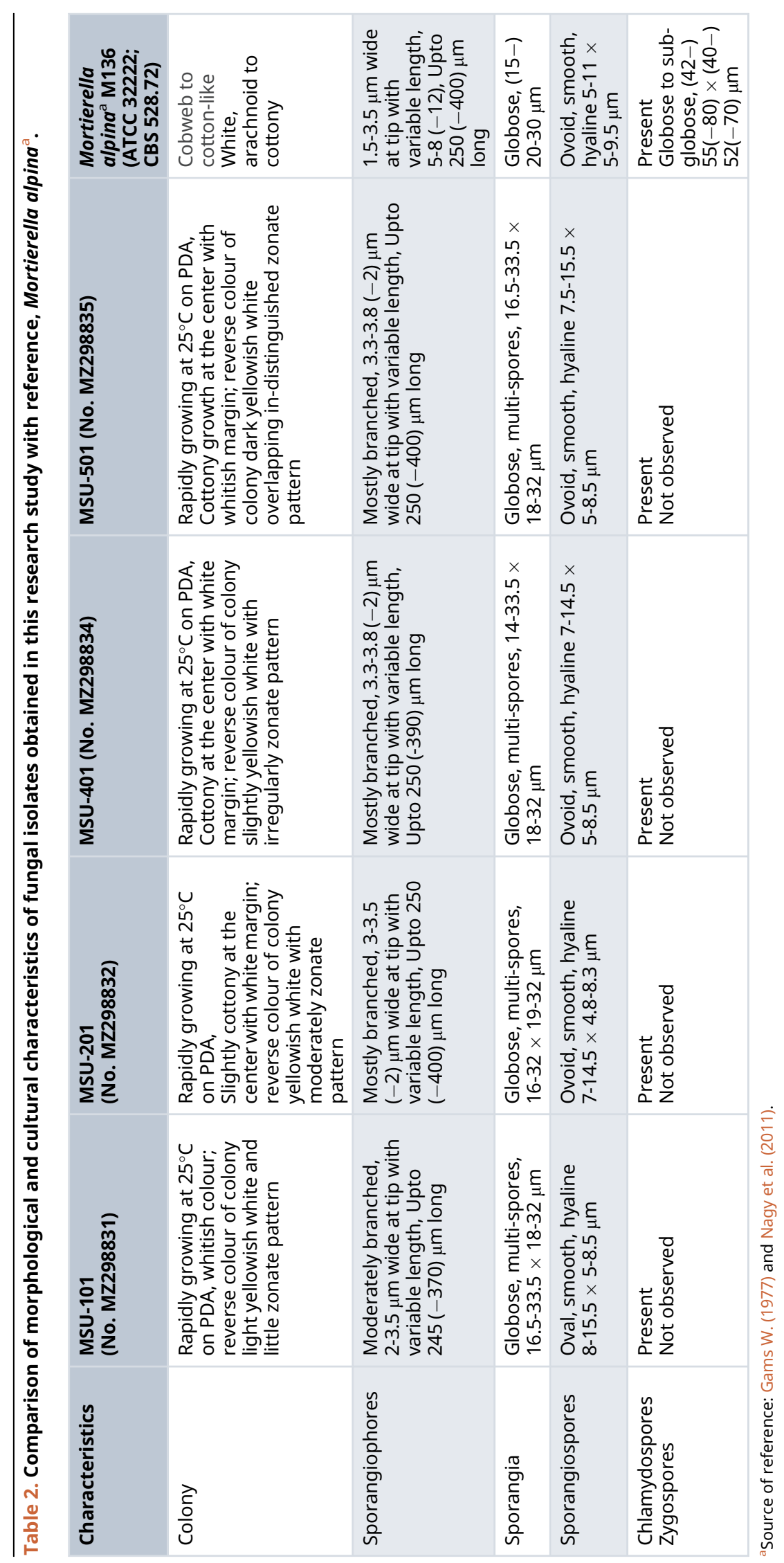


fungal cultures after 5 days incubation at $25^{\circ} \mathrm{C}$ ) in PDA slant tubes and stored in $20 \%$ glycerol at $-80^{\circ} \mathrm{C}$ in a cold chamber of the university microbiology laboratory. Later, all four cultures were barcoded as MSU-101, MSU-201, MSU-401 and MSU-501 and deposited at MSU Culture Collection Center, Management and Science University, Shah Alam, Selangor, Malaysia.

Genomic DNA extraction and sequence alignment

Total genomic DNA (gDNA) was extracted according to the standardized protocol (Tamura et al. 2013). ITS and rDNA conserved regions were amplified using ITS4 (5'-GGAAGTAAAAGTCGTAACAAGG-3') and ITS1 (5'TCCTCCGCTTATTGATATGC-3')

Total genomic DNA (gDNA) was extracted directly from the mycelia of fungal isolates, using Genomic DNA reparation Kit (KIT-1200-50: Fungal DNA Barcoding Kit, Apical Scientific Sdn Bhd Malaysia, following the manufacturer's instructions). Step by step protocol of gDNA isolation includes $1.500 \mu \mathrm{L}$ of Fungal Lysis Buffer added into $1.5 \mathrm{~mL}$ micro-centrifuge tube that contains the $1 \mathrm{~cm}$ agar cube of pure fungal culture. 2. $3 \mu \mathrm{L}$ of Proteinase $\mathrm{K}$ solution added. Vortex to mix and spin down briefly. 3. The tubes were incubated at $56^{\circ} \mathrm{C}$ for overnight and centrifuged the lysate at 14,000 to $16,000 \times \mathrm{g}$ for 10 minutes. 4 . Transferred $\sim 500 \mu \mathrm{L}$ of supernatant to a new $1.5 \mathrm{~mL}$ micro-centrifuge tube, which contains $500 \mu \mathrm{L}$ of isopropanol. The tube was inverted several times to mix gently. 6 . Centrifuged at 14,000 to $16,000 \times \mathrm{g}$ for $10 \mathrm{~min}$ and the supernatant was discarded. $7.1 \mathrm{~mL}$ of $70 \%$ ethanol was added, centrifuged again at 14,000 to $16,000 \times \mathrm{g}$ for $5 \mathrm{~min}$ and the supernatant was discarded. 8 . The pallet was air dried for $3 \mathrm{~min}$, resuspended with $50 \mu \mathrm{L} \mathrm{TE}$ Buffer and incubated at $56^{\circ} \mathrm{C}$ for $<1 \mathrm{hr}$. 9. Optical density (OD) was measured reading using spectrophotometer (Thermo Scientific, USA) and the nucleic acid was diluted to 15 to $25 \mathrm{ng} / \mu \mathrm{L}$ and $2 \mu \mathrm{L}$ of diluted nucleic acid was used as DNA template for PCR. 10. PCR mix was prepared according to manufacturer's instructions and $2 \mu \mathrm{L}$ of DNA template was added with each $23 \mu \mathrm{L}$ of PCR mix into $0.2 \mathrm{~mL}$ tube or 96-well plate. 11 . PCR cycle protocol was run on thermocycler and $\sim 700$ bp PCR products were checked on $1 \%$ agarose gel (First Base NGS KIT, Malaysia) and sequenced by ABI3100 sequencer. 12. After the sequencing results were ready, the reads were trimmed off with quality value $(\mathrm{QV})<20$, after that the forward and reverse sequencing results were aligned. 13. The obtained sequences were compared against the earlier submitted NCBI database using the BLAST algorithm (Kimura 1980) to verify the percentage of identity corresponding to the analysed species (Table 2). 13. The fungal sequences were aligned using Clustal_X v.2.1 and neighbour joining based phylogenetic tree was constructed using Mega (molecular evolutionary genetic analysis) X software version 16.04.4 (with unity desktop, ANALYZE mode; Tamura et al. 2013) to observe the grouping of obtained novel fungal species sequences (Kimura 1980; Nagy et al. 2011; Chien et al. 1974).

\section{Results and discussion}

Morphological confirmation

On the basis of morphological and cultural characteristics, the fungal isolates were confirmed and belong to Mortierella genus. Colonies of oleaginous fungal isolates after seven days of incubation at $25^{\circ} \mathrm{C}$ on PDA, were sporulating, fast growing, producing a concentric pattern, had flower-shaped radial growth, and were yellowish to whitish in color as depicted in Figure 1 (Eltariki, Tiwari, \& Alhoot, 2021). The detailed descriptions of morphological characteristics such as sporangiophores, sporangium, sporangiospores with reference M. alpina (ATCC 32222; CBS 528.72) isolate are given in Table 3 and Figure 2. Distinguishing prominent features between four fungal isolates (Barcoded as MSU-101, MSU-201, MSU-401 and MSU-501) were growth pattern, margin and colour of the colony on PDA medium in front and back side as shown in Figure 1, which requires further investigation. Thus, these four novel isolates were examined for molecular characterization and genetic diversity.

\section{Molecular characterization and genetic diversity}

In the ITS sequences analysis based on BLASTn (Basic Local Alignment Search Tool for nucleotides), MSU-101, MSU-201, MSU-401 and MSU-501 isolates were fall within the order Mortierellales as depicted in Figures 3 and 4, which matches with morphological identification of isolates as described above. These four fungal isolates (barcoded as MSU-101, MSU-201, MSU-401 and MSU-501) were compared and aligned with earlier submitted closely related species sequences by multiple sequence alignment (FASTA format) with software Clustal_X v.2.1. The phylogenetic tree constructed by neighbour joining mode with 1000 bootstrap values, showed that four oleaginous fungal isolates were $100 \%$ similar with earlier M. alpina genomes sequences submitted in GenBank NCBI (closest matching GenBank accession numbers were: EU918703; KX343169; FJ025186; FN689671; FN391358; FJ025158) as shown in Table 2 and Figures 3 and 4 . Thus, these isolates were identified as M. alpina species. The ITS sequences of these fungal isolates were deposited in GenBank with accession number of MZ298831:MZ298835. 

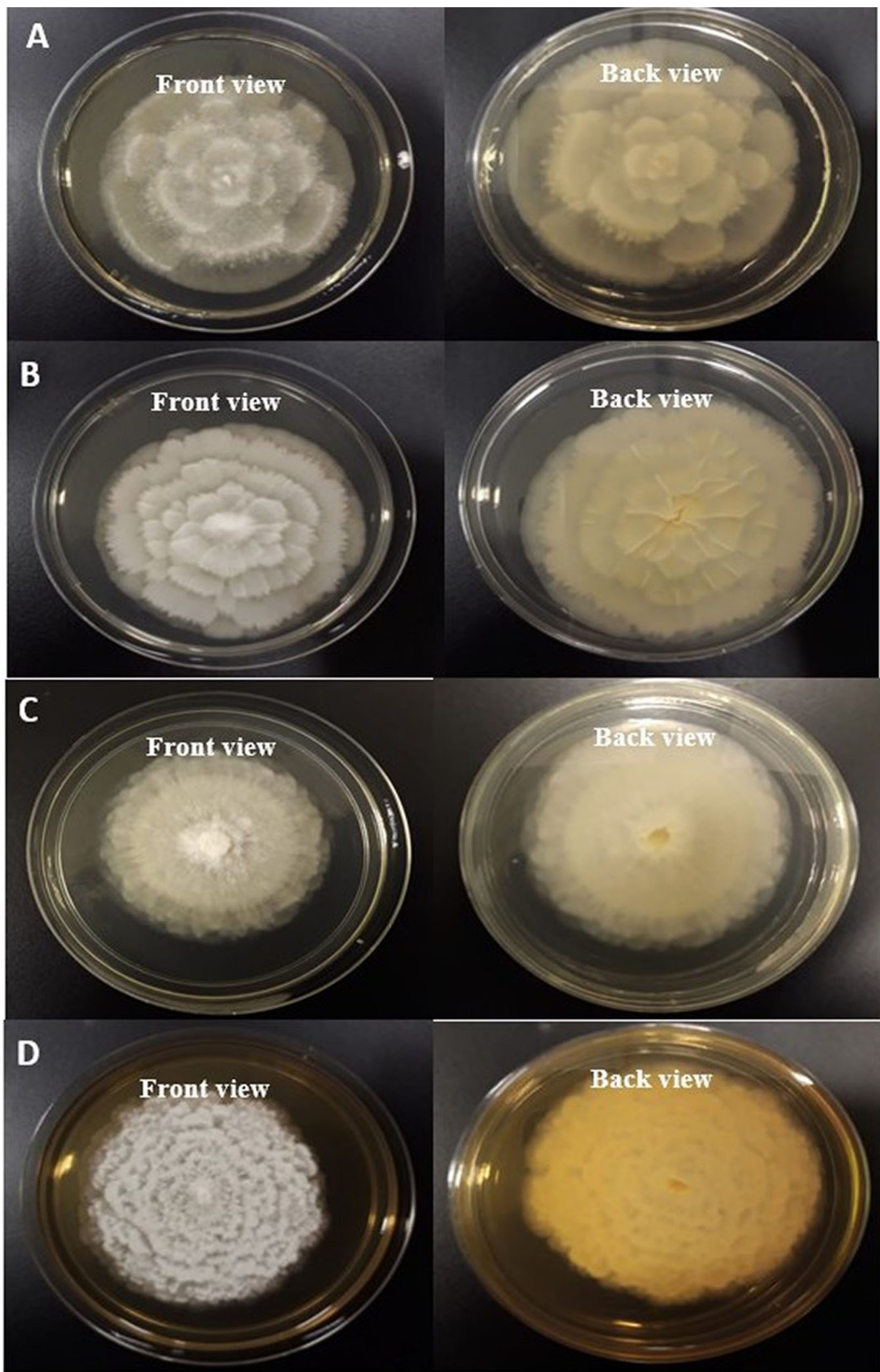

Figure 1. Colonies of fungal isolates on potato dextrose agar (PDA) medium (front view and back view) after 7 days of incubation at $25^{\circ} \mathrm{C}$. (A) MSU-101 colonies on PDA front and back view. (B) MSU-201 colonies on PDA front and back view. (C) MSU-401 colonies on PDA front and back view. (D) MSU-501 colonies on PDA front and back view. 


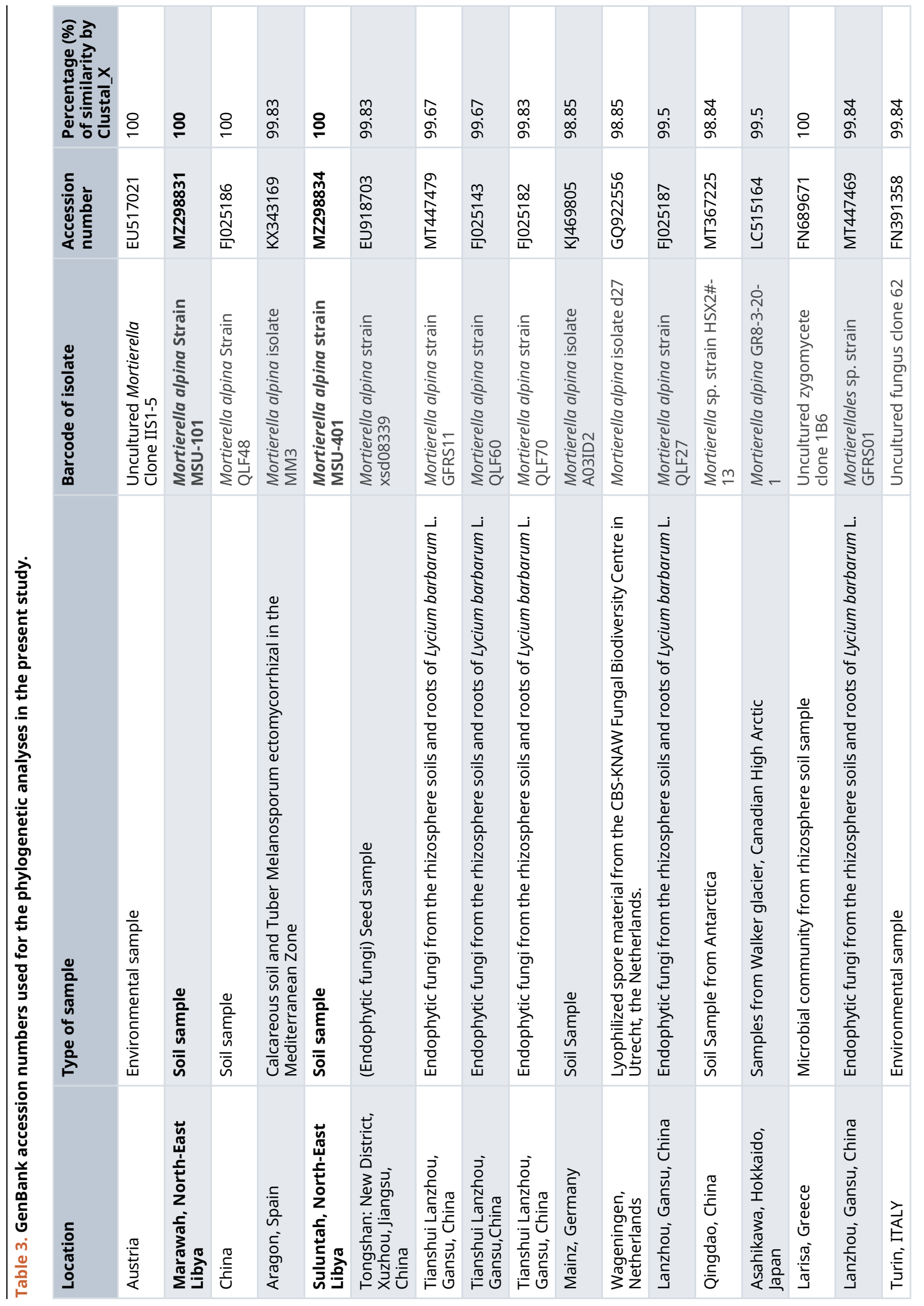




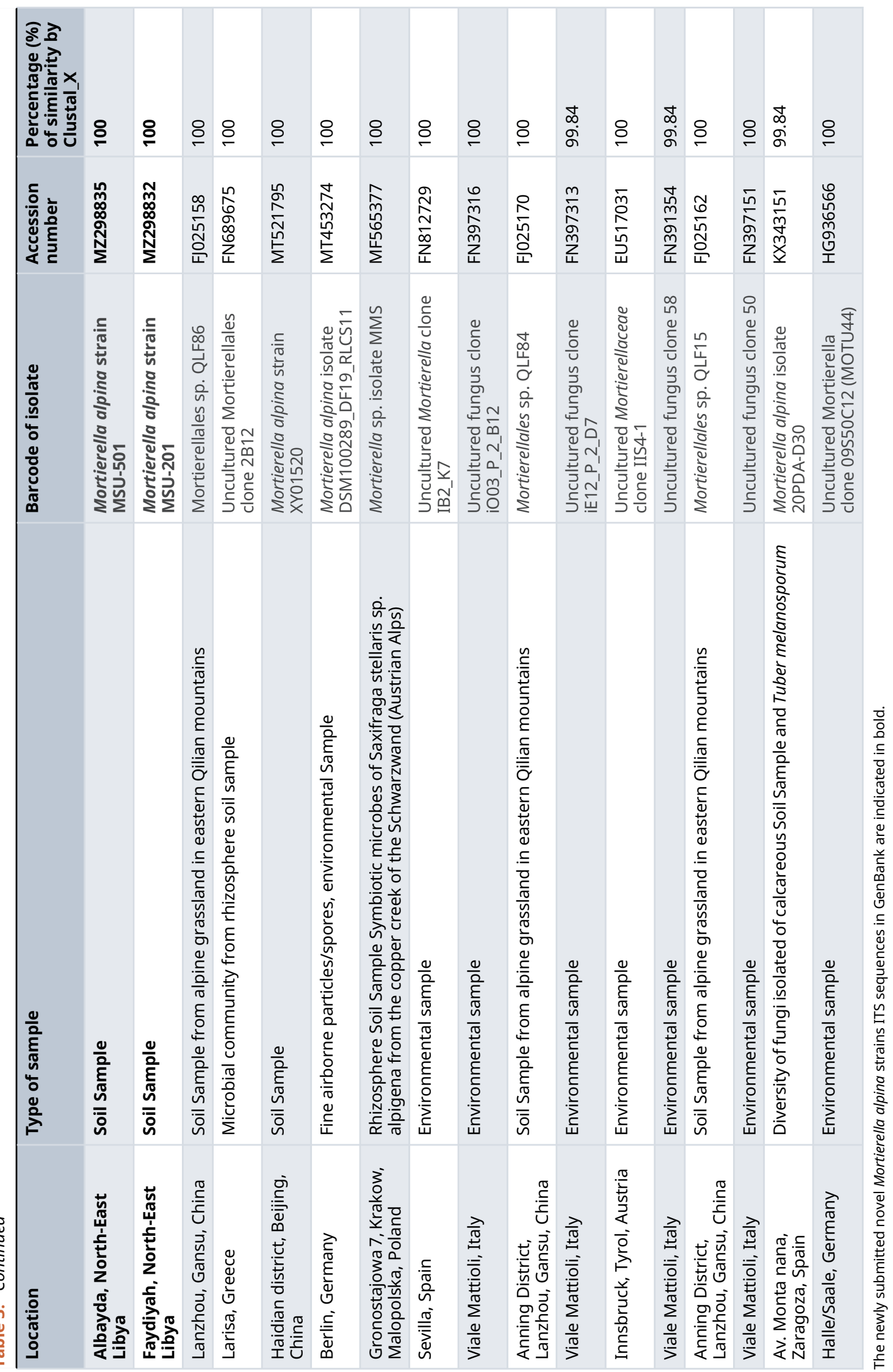



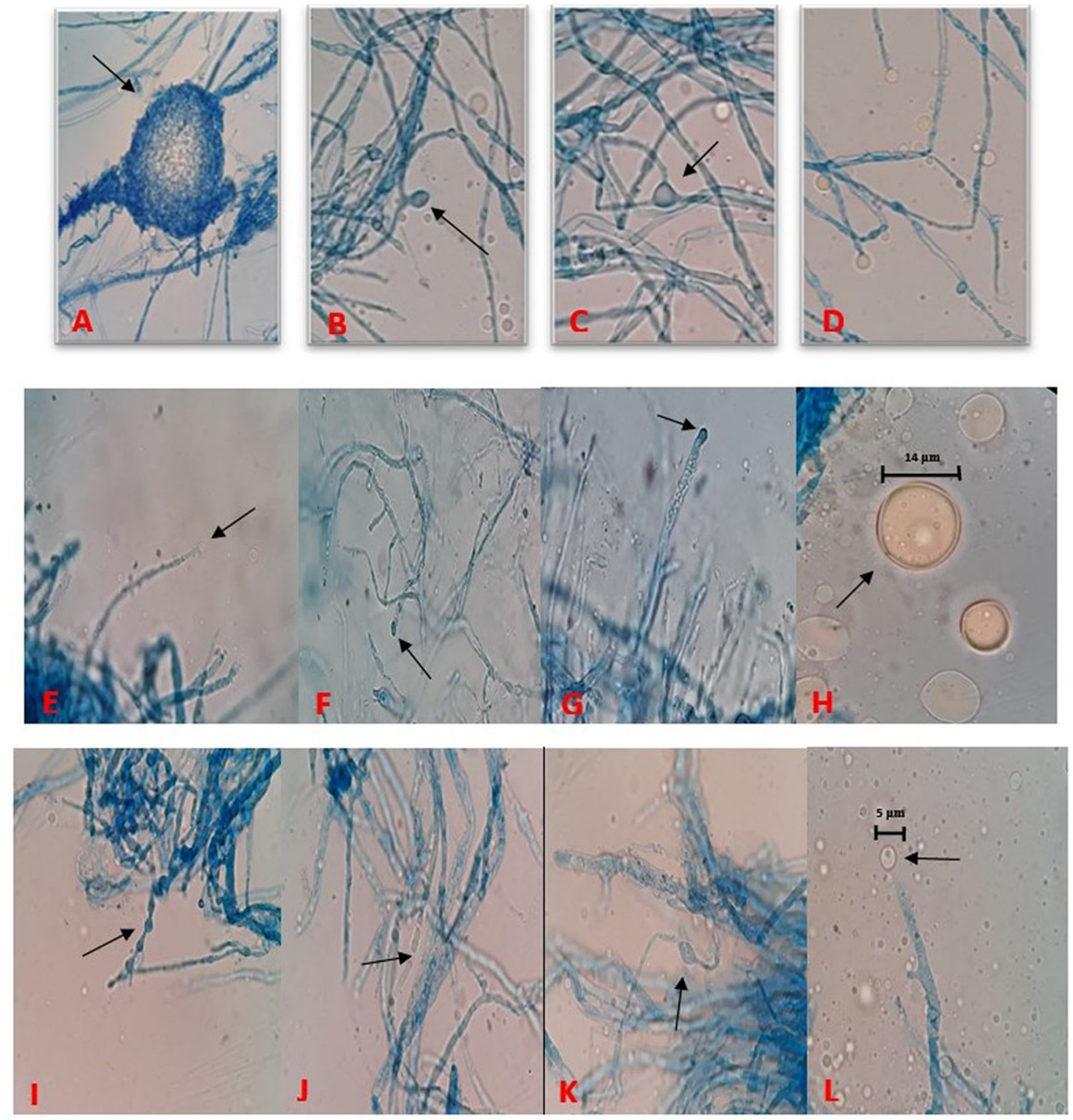

Figure 2. (A) Meiospore of MSU-101 isolate. (B) Immature sporangia from branched sporangiophore of MSU-101. (C) Intercalary chlamydospore of MSU-101 isolate. (D) Hyaline and ovoid sporangia, MSU-201 isolate. (E) Developing sporangia on single sporangiophore, MSU-201 isolate. (F) Immature young sporangia on highly branched sporangiophore, MSU-201. (G) Immature young sporangia on highly branched sporangiophore, MSU-401. (H) Mature globose sporangium containing sporangiospores, MSU-401. (I) Terminal chlamydospores with papillate ornamentation and hyphal segment remaining at the distal end, MSU-501. (J) Net of hypha with branching and septation, MSU-501. (K) Net of hypha with branching and chlamydospore, MSU-501. (L) Developing sporangium at tip on sporangiophore, MSU-501.

The present study added on the Mortierella alpina fungal strains reference collections and describes the diversity of these strains with known strains to date as shown in Figures 1 and 2. These novel Mortierella isolates add on to a large contribution of fungal diversity collections all over the world but still there is a plenty of room for more comprehensive $M$. alpina collections from Libya and this is the limitation of the present study. Thus, further research work needs to be carried out in future so that the hidden Mortierella fungal diversity and their SCO production potential can be harnessed. 


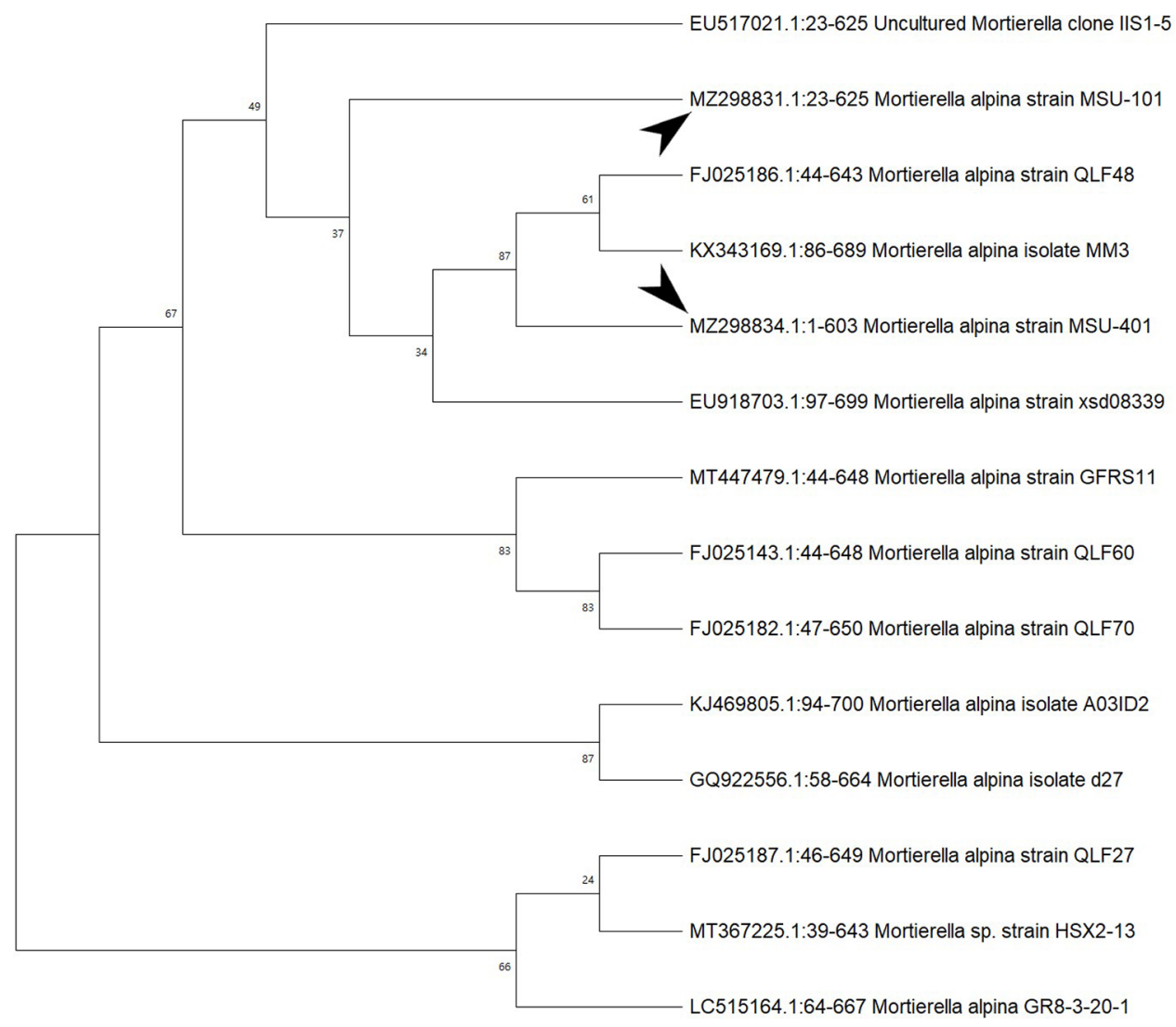

Figure 3. Neighbour joining method based phylogenetic tree from internal transcribed spacer conserved sequences of isolates MSU-101 and MSU-401. Bootstrap support values are indicated at the nodes.

Chen and Ho (2008) reported the significance of internal transcribed spacer region (18S-28S ribosomal gene) for the genetic characterization and these strains and found that the 5.8 rDNA regions of $M$. alpina isolates were conserved except some identified polymorphic sites. Furthermore, the interpretation was made that the variability is present in ITS1 and ITS2 regions, as there was no polymorphic site in the 5.8 rDNA region. Thus, it was evident that the ITS region could be used to confidently discriminate between M. alpina and other closely related species. These researchers also highlighted that NJ (Neighbour-Joining phylogenetic tree) tree analysis provides precise genetic diversity between M. alpina strains to come out with significant interpretation and conclusion.

Many species of Mortierella are potentialistic producers of C18 and C20 PUFAs (polyunsaturated fatty acids) such as $\gamma$-linolenic acid and arachidonic acid. M. alpina species is quite famous for the production of single cell oils as describes and reported by multiple scientist's time by time (Chien et al. 1974; Huang et al. 2013; Tamayo-Velez and Osorio 2018; Osorio and Habte 2014; Ellegaard et al. 2013; Lee et al. 2015; Nguyen and Lee 2016; Hwang et al. 2005; Shin et al. 2005; Tiwari and Razip 2020; Tiwari and Ganesen 2020; Maitig et al. 2028; Khan et al. 2018; Asdren and Faizal 2018 ; Yu et al. 2019; Alhoot et al. 2019; Tiwari et al. 2018, 2019a,b).

Research scientists are working to remodel these novel strains so that the SCO production can be enhanced at industrial scale. Shimizu and Sakuradani (2009) reported M. alpina 1S-4 strain by extensive screening, for the large-scale production of variety of PUFAs. This isolate not only had the potential for SCO production but also had several advantages to work as a model for lipogenesis studies. Thus, we can anticipate from earlier published data that the isolates reported from present study can be useful for bioprospecting in terms of single cell oil production. However, the oil production potential of these oleaginous fungal isolates is under investigation and our research group is presently working in this direction to assess the SCO potential of these diverse isolates obtained from Libyan soil. 


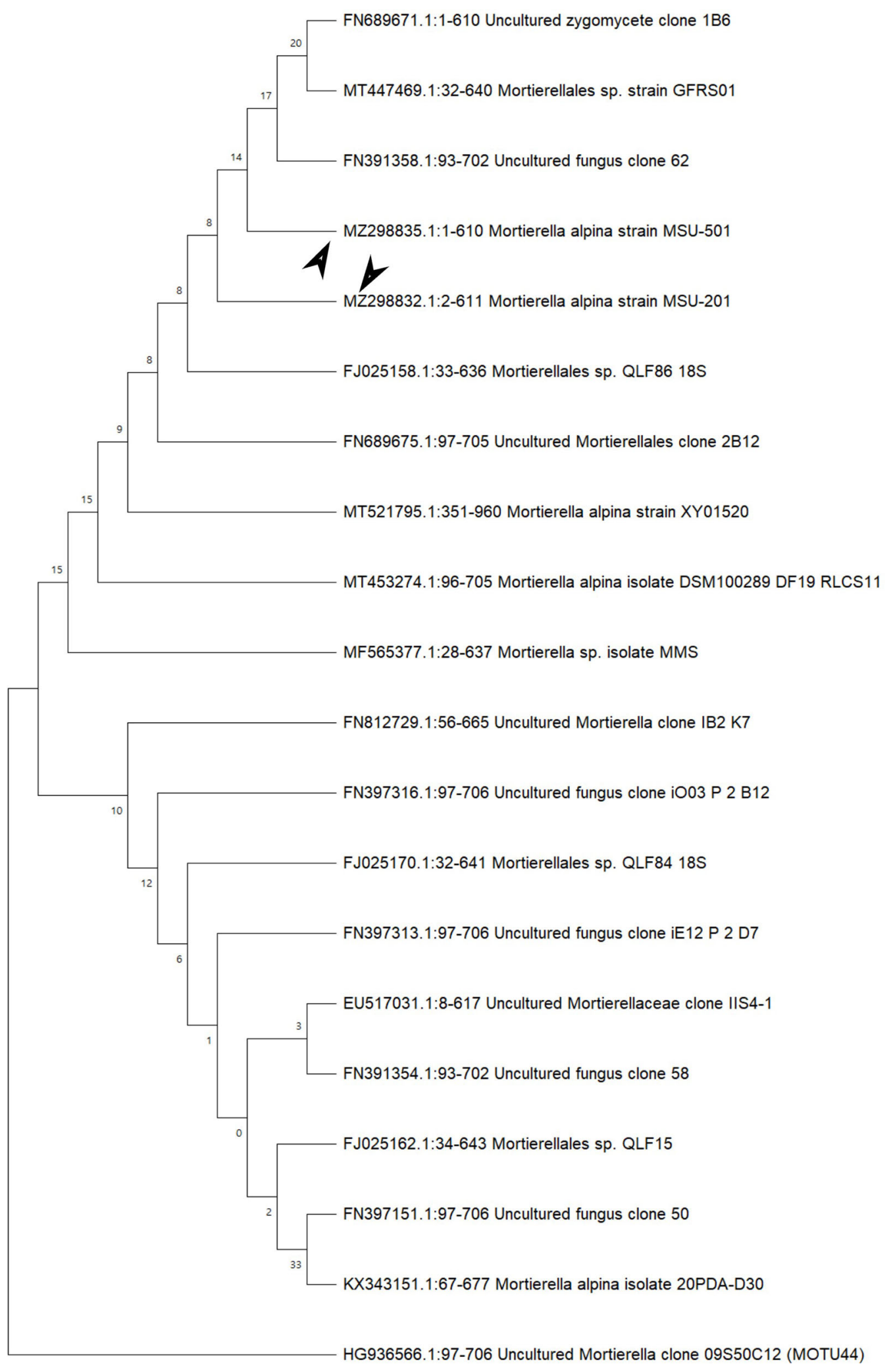

Figure 4. Neighbour joining method based phylogenetic tree from internal transcribed spacer conserved sequences of isolates MSU-201 and MSU-501. Bootstrap support values are indicated at the nodes. 


\section{Conclusion}

In the present study, four oleaginous fungal isolates barcoded as MSU-101, MSU-201, MSU-401 and MSU-501 were identified and confirmed by morphological and molecular analysis. These fungal isolates had shown highest similarity with Mortierella alpina species and can be potential single cell oil producers, further research work is in progress for assessment and exploitation of these isolates in terms of oil production.

\section{Data availability}

NCBI GenBank: Accession numbers MZ298831 to MZ298835.

https://www.ncbi.nlm.nih.gov/nuccore/?term=MZ298831:MZ298835[accn].

Zenodo: Molecular characterization and genetic diversity of four undescribed novel oleaginous Mortierella alpina strains from Libya. https://doi.org/10.5281/zenodo.5239888 (Eltariki, Tiwari, \& Alhoot, 2021).

This project contains the following underlying data:

- Developing sporangia on single sporangiophore, MSU-201 isolate.jpg

- Developing sporangium at tip on sporangiophore, MSU-501.jpg

- Hyaline and ovoid sporangia, MSU-201 isolate.jpg

- Immature sporangia from branched sporangiophore of MSU-101.jpg

- Immature young sporangia on highly branched sporangiophore, MSU-201.jpg

- Immature young sporangia on highly branched sporangiophore, MSU-401.jpg

- Intercalary chlamydospore of MSU-101 isolate.jpg

- Meispore of MSU-101 isolate.jpg

- Mortierell alpina (4 strains) gel image.jpg

- Mortierella alpina novel strain-MSU-201_Front view.jpg

- Mortierella alpina novel strain_MSU-101.jpg

- Mortierella alpina novel strain_MSU-101_Back view.jpg

- Mortierella alpina novel strain_MSU-201_Back view.jpg

- Mortierella alpina novel strain_MSU-401_Back view.jpg

- Mortierella alpina novel strain_MSU-401_Front view.jpgMortierella alpina novel strain_MSU-501_Back view.jpg

- Mortierella alpina novel strain_MSU-501_Front view.jpg

- Net of hypha with branching and chlamydospore, MSU-501.jpg

- Net of hypha with branching and septation, MSU-501.jpg

- Phylogenetic tree MSU-101 and MSU-401.jpg

- Phylogenetic tree_MSU-201 and MSU-501.jpg 
- Terminal chlamydospores with papillate ornamentation and hyphal segment remaining at the distal end, MSU-501.jpg

- Terminal chlamydospores.jpg

Data are available under the terms of the Creative Commons Attribution 4.0 International license (CC-BY 4.0).

\section{Acknowledgements}

Authors would like to thank Management and Science University (MSU), Malaysia for the research laboratory facilities. The laboratory research work has been carried out by Miss Fuzia Elfituri Muftah Eltariki from Libya for the fulfilment of her Ph.D. degree under the supervision of Dr. Mohammed Abdelfatah Alhoot and Dr. Kartikeya Tiwari. All authors have given consent for acknowledgement. An earlier version of this article can be found on Research Square (DOI: https://doi. org/10.21203/rs.3.rs-673772/v1).

\section{References}

Alhoot MA, Eltraiki MEF, Ridzuan PM, et al.: The inhibitory effect of the Mentha piperita leaves extracts on the mycotoxin producer Aspergillus niger. Int. J. Med. Tox. Legal Med. 2019; 22(1-2): 179-183.

Ariyawansa HA, Hyde KD, Jayasiri SC: Fungal diversity notes 111-252 taxonomic and phylogenetic contributions to fungal taxa. Fungal Divers. 2015; 75: 27-274.

Publisher Full Text

Asdren Z, Faizal MZ: Investigation of potential antibacterial activity of Salvadora persica in combination with Mentha arvensis against Staphylococcus spp. 2018; 21(3-4): 288-292.

Chien CY, Kuhlman EG, Gams W: Zygospores in two Mortierella species with "stylospores". Myco. 1974; 66: 114-121.

Coemans E: Quelques hyphomycetes nouveaux. - Ire. - I. Mortierella polycephala et II. Martensella pectinata. Bull I' Acad Royale Sci, Lett, Beaux-Arts Belgique. Ser. 2. 1863; 15: 536-544.

Degawa Y, Gams W: A new species of Mortierella, and an associated sporangiiferous mycoparasite in a new genus. Nothadelphia Stud. Myco. 2004; 50: 576-572.

Ellegaard-Jensen L, Aamand J, Kragelund BB: Strains of the soil fungus Mortierella show different degradation potentials for the phenylurea herbicide diuron. Biodegradation. 2013; 24: 765-774.

PubMed Abstract | Publisher Full Text

Eltariki FEM, Tiwari K, Alhoot MA: Molecular characterization and genetic diversity of four undescribed novel oleaginous Mortierella alpina strains from Libya (Mega $X$ software 16.04.4 (with unity desktop, ANALYZE mode)). Zenodo. 2021.

Publisher Full Text

Gams W: A key to the species of Mortierella. Persoonia. 1977; 9: 381-391. Ha SJ, Park CS, Ryu YW: Selection of organic nitrogen source and optimization of culture conditions for the production of arachidonic acid from Mortierella alpina. Korean J. Biotech. Bio. 2004; 19: 78-82.

Hibbett DS, Binder M, Bischoff JF: A higher-level phylogenetic classification of the fungi. Mycol. Res. 2007; 111: 509-547.

PubMed Abstract | Publisher Full Text

Hoffmann K, Pawłowska J, Walther G: The family structure of the Mucorales: a synoptic revision based on comprehensive multigenegenealogies. Persoonia. 2013; 30: 57-76.

PubMed Abstract | Publisher Full Text | Free Full Text

Huang C, Chen XF, Xiong L: Single cell oil production from low-cost substrates: the possibility and potential of its industrialization.

Biotech. Adv. 2013; 31: 129-139.

PubMed Abstract | Publisher Full Text

Hwang $\mathrm{BH}$, Kim JW, Park CY, et al.: High-level production of arachidonic acid by fed-batch culture of Mortierella alpina using $\mathrm{NH}_{4} \mathrm{OH}$ as a nitrogen source and pH control. Biotech. Lett. 2005; 27: 731-735. PubMed Abstract | Publisher Full Text

Hyde KD, Hongsanan S, Jeewon R: Fungal diversity notes 367-490: taxonomic and phylogenetic contributions to fungal taxa. Fungal Divers. 2016; 80: 1-270. 10.1007/s13225-016-0373-x
Khan J, Mohammed K, Kaur N, et al.: Synthesis of cinnamic acid amide derivatives and the biological evaluation of a-glucosidase inhibitory activity. Int. J. Med. Tox. Legal Med. 2018; 21(3-4): 216-220.

Publisher Full Text

Kimura MA: Simple method for estimating evolutionary rates of base substitutions through comparative studies of nucleotide sequences. J. Mol. Evo. 1980; 16: 111-120.

PubMed Abstract | Publisher Full Text

Kirk PM: Mortierella elongata. IMI Description Fungi Bact. 1997; 1303: 1-2. Lee HY, Nguyen TT, Mun HY: Confirmation of two undescribed fungal species from Dokdo of Korea based on current classification system using multi loci. Mycobiology. 2015; 43: 392-401.

PubMed Abstract | Publisher Full Text | Free Full Text

Linnemann G: Die Mucorineen-Gattung Mortierella Coemans. Pflanzenforschung. 1941; 23: 1-64.

Maitig AMA, Alhoot MAM, Tiwari K: Isolation and screening of extracellular protease enzyme from fungal isolates of soil. J. Pure Appl. Microbio. 2018; 12(4): 2059-2067.

Publisher Full Tex

Nagy NG, Petkovits T, Kovács GM, et al.: Where is the unseen fungal diversity hidden? A study of Mortierella reveals a large contribution of reference collections to the identification of fungal environmental sequences. New Phytol. 2011; 191: 789-794.

PubMed Abstract | Publisher Full Text

Nguyen TTT, Lee HB: Characterization of a zygomycete fungus, Mortierella minutissima from freshwater of Yeongsan river in Korea. Kor. J. Mycol. 2016; 44: 346-349.

Osorio NW, Habte M: Soil phosphate desorption induced by a phosphate-solubilizing fungus. Comm. Soil Sci. Plant Anal. 2014; 45: 451-460.

Publisher Full Text

Rhie SG, Kang HY, Park YJ: The effects of Mortierella alpina fungi and extracted oil (arachidonic acid rich) on growth and learning ability in dam and pups of rat. J. Korean Soc. Food Sci. Nutri. 2002; 31: 1084-1091. Publisher Full Text

Rhie SG, Park YJ: The growth effects of Mortierella alpina contained diets and burn healing effects of Mortierella alpina extracted oil (arachidonic acid rich) in rat. Thesis Collect. Univer. Suwon. 2001; 19: 285-297.

Shin HS, Oh IH, Lee JH: Isolation and production of arachidonic and eicosapentaenoic acid by fungi. J. Ind. Tech. 1994; 2: 43-52. PubMed Abstract | Publisher Full Text

Shin HT, Lee SW, Park KM, et al.: Characteristics of submerged and solidstate fermentations for production of arachidonic acid by Mortierella alpina. Korean J. Biotech. Bio. 2005; 20: 60-65.

Shimizu S, Sakuradani E: Single cell oil production by Mortierella alpina. J. Biotech. 2009; 144: 31-36.

PubMed Abstract | Publisher Full Text

Spatafora JW, Chang Y, Benny GL: A phylum-level phylogenetic classification of zygomycete fungi based on genome-scale data. 
Mycologia. 2016; 108: 1028-1046.

PubMed Abstract | Publisher Full Text | Free Full Text

Tamura K, Stecher G, Peterson D, et al.: MEGA6: molecular evolutionary

genetics analysis version 6.0. Mol. Biol. Evol. 2013; 30: 2725-9.

PubMed Abstract | Publisher Full Text | Free Full Text

Tamayo-Velez A, Osorio NW: Soil fertility improvement by litter decomposition and inoculation with the fungus Mortierella sp. in avocado plantations of Colombia. Comm. Soil Sci. Plant Anal. 2018; 49: 139-147.

Tiwari K, Razip NAFBM: Antagonistic activity and molecular characterization of endophytic biocontrol agent Trichoderma

harzianum fungal strains isolated from medicinal plant Terminalia catappa L. in West Malaysia. Int. J. Med. Tox. Legal Med. 2020; 23(3-4):

48-53.

Publisher Full Text

Tiwari K, Ganesen M: Novel endophytic Penicillium chrysogenum strains isolated from Plectranthus amboinicus L. of West Malaysia. Res. J. Microbio. 2020; 15(1): 15-21.

Tiwari K, Alhoot MA, Eltraiki MEF, et al.: Prevalence and genetic diversity assessment of mycotoxigenic Colletotrichum gleosporioides in

wheat grains collected from different regions of Libya. Int. J. Med. Tox. Legal Med. 2019a; 22(1-2): 184-185.
Tiwari K, Alhoot MA, Sharma AK: Paclitaxel of fungal origin: challenges and updates. Int. J. Med. Tox. Legal Med. 2019b; 22(1-2) 160-161.

Publisher Full Text

Tiwari K, Alhoot MA, Eltraiki MEF: Occurrence and prevalence of mycotoxigenic Fusarium solani in onion samples collected from different regions of Libya. Asian J. Biol. Sci. 2018; 11(4): 192-196. Publisher Full Text

Wang L, Chen W, Feng Y, et al.: Genome characterization of the oleaginous fungus Mortierella alpina. PLoS One. 2011; 6: e28319. PubMed Abstract | Publisher Full Text | Free Full Text

Wagner L, Stielow B, Hoffmann K: A comprehensive molecular phylogeny of the Mortierellales (Mortierellomycotina) based on nuclear ribosomal DNA. Persoonia. 2013; 30: 77-93. PubMed Abstract | Publisher Full Text | Free Full Text

White TJ, Bruns T, Lee S, et al.: Amplification and direct sequencing of fungal ribosomal RNA genes for phylogenetics. In: Innis MA, Gelfand DH, Sninsky J, et al., editors. PCR protocols: a guide to methods and applications. San Diego: Academic Press; 1990; 315-22.

Yu K-X, Norhisham SN, CH NG: Antimicrobial potential of Padina australis and Sargassum polycystum against respiratory infection causing bacteria. Int. J. Med. Tox. Legal Med. 2019; 22(1-2): 138-141. 


\section{Open Peer Review}

\section{Current Peer Review Status:}

\section{Version 1}

Reviewer Report 02 November 2021

https://doi.org/10.5256/f1000research.74246.r93646

(C) 2021 Singh A. This is an open access peer review report distributed under the terms of the Creative Commons Attribution License, which permits unrestricted use, distribution, and reproduction in any medium, provided the original work is properly cited.

\section{Abhijeet Singh \\ Department of Biosciences, Manipal University Jaipur, Jaipur, India}

The research study addresses and discusses the novel strains isolation, identification and genetic diversity assessment by standard protocols. The conserved internal transcribed spacer regions amplified and probably gives idea about the specific region in internal transcribed spacer for loci in terms of bioprospecting and exploitation of these novel strains for single soil production. The methodology discusses the isolation, identification and molecular characterization of $M$. alpina strains from Al-Jabal Alakdar (Northeast of Libya). The novel strains sequences submitted in NCBI GenBank with specific barcode (barcoded as MSU-101, MSU-201, MSU-401 and MSU-501) (accession no. MZ298831: MZ298835) and cultures preserved at Culture Collection Center of University. Thus, the research work is accepted and recommended for indexing.

Is the work clearly and accurately presented and does it cite the current literature? Yes

Is the study design appropriate and is the work technically sound? Yes

Are sufficient details of methods and analysis provided to allow replication by others? Yes

If applicable, is the statistical analysis and its interpretation appropriate? I cannot comment. A qualified statistician is required.

Are all the source data underlying the results available to ensure full reproducibility? Yes

Are the conclusions drawn adequately supported by the results? Yes 
Competing Interests: No competing interests were disclosed.

Reviewer Expertise: Molecular Biology, Bionanotechnology

I confirm that I have read this submission and believe that I have an appropriate level of expertise to confirm that it is of an acceptable scientific standard.

Reviewer Report 02 November 2021

https://doi.org/10.5256/f1000research.74246.r93650

(C) 2021 Singh Gour D. This is an open access peer review report distributed under the terms of the Creative Commons Attribution License, which permits unrestricted use, distribution, and reproduction in any medium, provided the original work is properly cited.

\section{Digpal Singh Gour}

${ }^{1}$ Department of Fish and Wildlife Sciences, University of Idaho, Moscow, ID, USA

2 Genomic Resource Core, Institute for Bioinformatics \& Evolutionary Studies, University of Idaho, Moscow, ID, USA

The research study documented four novel M. alpina strains to produce single cell oil and describes the isolation, identification, and molecular characterization of $M$. alpina strains from alJabal al-Akhdar (Northeast of Libya) by standard protocols. The conserved internal transcribed spacer regions amplified, and assessment of genetic diversity carried out in this research work.

The novel strains sequences submitted in NCBI GenBank with specific barcodes (barcoded as MSU-101, MSU-201, MSU-401, and MSU-501) (accession no. MZ298831: MZ298835) were given.

However, further research work in connection with single cell production can be done and set a benchmark for bioprospecting in the future. I hope in future the work will be carried out in this direction. As far as the present research study is concerned, the novel strains are described, organized, and documented, thus accepted for indexing.

Is the work clearly and accurately presented and does it cite the current literature? Yes

Is the study design appropriate and is the work technically sound?

Yes

Are sufficient details of methods and analysis provided to allow replication by others? Yes

If applicable, is the statistical analysis and its interpretation appropriate? Not applicable

Are all the source data underlying the results available to ensure full reproducibility? 
Yes

Are the conclusions drawn adequately supported by the results?

Yes

Competing Interests: No competing interests were disclosed.

Reviewer Expertise: Genetics \& Genomics

I confirm that I have read this submission and believe that I have an appropriate level of expertise to confirm that it is of an acceptable scientific standard.

Reviewer Report 17 September 2021

https://doi.org/10.5256/f1000research.74246.r93648

(C) 2021 Kesari K. This is an open access peer review report distributed under the terms of the Creative Commons Attribution License, which permits unrestricted use, distribution, and reproduction in any medium, provided the original work is properly cited.

\section{Kavindra Kumar Kesari}

Department of Applied Physics, School of Science, Aalto University, Espoo, Finland

\section{Comments:}

Justification on the research work shown is manuscript is profound and significant since the research manuscript describes valuable information on Mortierella alpina novel strains isolated from Libya.

Stepwise flowsheet and methodology discuss the isolation, identification and molecular characterization of M. alpina strains from Al-Jabal Alakdar (Northeast of Libya).

Mortierella alpina strains are well known and documented for the potential of single cell oil production (SCO) at large scale. So, the conserved internal transcribed spacer regions amplification and assessment of genetic diversity carried out in this research work will give insight on future standard protocols and further work in this field for exploitation and production of arachidonic acid/poly-unsaturated fatty acids production. The novel strains sequences submitted in NCBI GenBank with specific barcode (barcoded as MSU-101, MSU-201, MSU-401 and MSU-501) (accession no. MZ298831: MZ298835) and cultures preserved at Culture Collection Center of University.

Further research work in connection with single cell production can be done and set a benchmark for bioprospecting in future. The work was carried out by a PhD candidate and will facilitate the career growth for the candidate for future opportunities and prospects.

Is the work clearly and accurately presented and does it cite the current literature? 
Yes

Is the study design appropriate and is the work technically sound?

Yes

Are sufficient details of methods and analysis provided to allow replication by others? Yes

If applicable, is the statistical analysis and its interpretation appropriate?

Yes

Are all the source data underlying the results available to ensure full reproducibility? Yes

Are the conclusions drawn adequately supported by the results?

Yes

Competing Interests: No competing interests were disclosed.

Reviewer Expertise: Cell and cancer biology; plant biotechnology; industrial microbiology

I confirm that I have read this submission and believe that I have an appropriate level of expertise to confirm that it is of an acceptable scientific standard.

The benefits of publishing with F1000Research:

- Your article is published within days, with no editorial bias

- You can publish traditional articles, null/negative results, case reports, data notes and more

- The peer review process is transparent and collaborative

- Your article is indexed in PubMed after passing peer review

- Dedicated customer support at every stage

For pre-submission enquiries, contact research@f1000.com

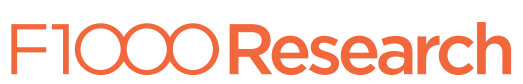

